\title{
Germanica
}

\section{Document sans titre}

\section{(2) OpenEdition \\ Journals}

Electronic version

URL: http://journals.openedition.org/germanica/2818

DOI: 10.4000/germanica.2818

ISSN: 2107-0784

Publisher

Université de Lille

\section{Printed version}

Date of publication: 30 June 1988

ISSN: 0984-2632

Electronic reference

«Document sans titre », Germanica [Online], 3 | 1988, Online since 10 July 2015, connection on 06 October 2020. URL : http://journals.openedition.org/germanica/2818; DOI : https://doi.org/10.4000/ germanica. 2818

This text was automatically generated on 6 October 2020 .

() Tous droits réservés 


\section{Document sans titre}

1 Il ne saurait être question, bien évidemment, d'alimenter ici le débat bruyant, ouvert naguère par $\mathrm{T}$. Todorov, sur l'éventuelle extinction du fantastique, et ses relèves présumées, dans l'art et la littérature «modernes ». Un arrêt qui, quoi qu'on en pense, trahit une belle présomption, puisqu'il suppose et engage rien moins qu'une orthodoxie du fantastique. On est revenu, depuis un certain temps déjà, sur ce point de vue normatif. Cependant, s'il est effectivement douteux de poser une orthodoxie en la matière, du moins peut-on reconnaitre qu'il existe bien un code fantastique de l'imaginaire. Un code qui s'affiche évidemment dans les œuvres qui se donnent l'étiquette de fantastiques, mais qui peut éventuellement fonctionner ailleurs, dans d'autres territoires. Repérer quelques uns de ces modes de fonctionnement - allégeance et détournement, citation et distanciation, aveu et parodie, etc... - est l'objet des études ici réunies. On posera ainsi quelques questions délibérément en marge, sur ces frontières où s'exerce encore et s'arrête l'efficacité fantastique : comment ce code vient subvertir arts et genres connexes (A.Combes, J.-J. Pollet); comment il entre en métaphysique (L.Vax) ou vient même nourrir une définition (une morale?) de l'inconscient (J. Bellemin-Noël) ; comment il déborde, éventuellement, l'espace culturel que lui assigne sa tradition (R. Boyer, H. Balzamo); comment il se parodie en des poétiques originales (P. Giraud, G. Roussel). Le fantastique comme champ exemplaire d'intertextualité. 